\title{
ONLINE EXHIBITIONS AND ARCHIVES : A COLLABORATIVE PROJECT FOR TEACHING AND LEARNING IN DESIGN
}

Jane Devine Mejia

Centre for Excellence in Teaching and Learning through Design

University of Brighton

Address 58-67 Grand Parade

Brighton, BN2 2JY

United Kingdom

jadm10@brighton.ac.uk

http://cetld.brighton.ac.uk/index.html

\begin{abstract}
This paper discusses the Centre for Excellence in Teaching and Learning through Design (CETLD) Online Exhibitions Project, a collaboration between the University of Brighton, the Royal Institute of British Architects, the Victoria and Albert Museum and the Royal College of Art. The project entailed creating a virtual exhibition drawn from the archives of the partner institutions, with the goal of encouraging students to use archives for practice-based inquiry and in historical/theoretical research. Designing an exhibition that incorporates student involvement through the use of Web 2.0 technologies has presented various challenges: technical, conceptual and pedagogical. The paper is thus a case study of how virtual access to archives can contribute to teaching and learning in the design disciplines.
\end{abstract}

\section{INTRODUCTION}

Since the 1990s, online exhibitions have been a way for museums and archives to promote public awareness of their collections. Many institutions also provide extensive image databases based on their holdings and offer online catalogues for researchers who need access to museum and archival materials. In March 2008 the Victoria and Albert Museum hosted a workshop entitled "Widening Access to the V\&A+RIBA Architecture Partnership Collections." The aim of this event was to explore how these important research collections could better support higher education (HE) courses in architecture, using both physical and online resources to broaden access for HE users. During the discussions, attendees from twelve UK HE institutions articulated the lack of clarity that they experienced in trying to find out what was in the archives and how to plan coursework around the collections. The implicit expectation in many museums and archives is that HE researchers should know how to find their 'way in' and what questions to ask of the archivists and curators. In the digital age, this assumption no longer holds true, as many users are further and further removed from hands-on primary research and rely increasingly on digital surrogates which are often only a partial representation of an archive's range and content.

With the establishment of the Centre for Excellence in Teaching and Learning through Design (CETLD) in 2005, four major UK institutions joined together to 
EVA 2009 London Conference 6-8 July

Jane Devine Mejia

collaborate on shared research objectives. CETLD is a five-year partnership between the University of Brighton, the Royal College of Art, the Royal Institute of British Architects (RIBA) and the Victoria and Albert Museum (V\&A) that aims to enhance learning and teaching in design through research that brings together resources and expertise from higher education and collections-based partners [1]. The archivists across the CETLD partnership saw this collaboration as an opportunity to explore how to engage practice-based design students and tutors with archival resources.

While most of the archivists had been involved in curating and contributing to physical exhibitions and, in the case of the RIBA and the V\&A, to the development of online versions of these exhibitions, none of the partners had developed a reusable online exhibition framework that would support teaching and learning in the design disciplines. The Online Exhibitions Project received CETLD funding for two years to support a part-time lead researcher, with archivists, curators, education specialists, tutors and students expected to volunteer their time as needed. Other members of the project team included CETLD ICT specialists Sina Krause and Roland Mathews and University of Brighton postgraduate student Heloisa Candello (through the 2008 CETLD Student Placement Programme), all of them contributing on a part-time basis.

The Online Exhibitions Project was divided into five main phases:

1. a survey of best practice in online exhibition design and a review of the literature on learning and teaching with virtual collections and online exhibitions

2. selection of the exhibition content using the CETLD partner collections, including consideration of learning and teaching potential and copyright issues related to digital images

3. development of the technological infrastructure for the exhibition

4. testing the Online Exhibition with design students and tutors in both practicebased areas and design history to assess its pedagogical value

5. using lessons learned from this experience to make recommendations on a sustainable online exhibition framework for the CETLD partner archives.

\section{INITIAL INVESTIGATION}

In conducting the literature review and survey of best practice, we looked at websites that had been received the annual Museums and the Web Online Exhibition Award, an international juried prize, from 1997-2008 [2]. We also assessed virtual exhibitions at major museums, library and archives such as the Smithsonian, the National Archives (UK) and the Cooper Hewitt National Design Museum. Our research indicated that scant attention is paid to $\mathrm{HE}$ as a principle audience for virtual exhibitions. Most of the art, archives and museum sites reviewed by the author and her student research assistant were conceived for the general public, and in some cases offered material for primary and secondary school audiences. While university archives, libraries and museums frequently produce virtual exhibitions relating to their collections, few are explicit about how these might be used in post-secondary teaching and learning and very few allow any form of HE student participation [3]. None of the literature on virtual exhibitions 
EVA 2009 London Conference 6-8 July

Jane Devine Mejia

that we reviewed dealt with how HE design students and educators might use them for practice-based learning.

In addition to the kind of professionally curated online exhibitions created for museums and archives, we studied the growing trend towards user-defined exhibitions based on institutional collections, like the Fine Arts Museums of San Francisco My Gallery and the Metropolitan Museum's My MetMuseum [4]. Empowering visitors to select digital images of museum objects and arrange them in online exhibitions without the mediation of museum staff changes the nature of interactions between museums, their collections and their virtual visitors by democratizing curatorship. The concept of user control was central to our investigation of how to develop a participative virtual exhibition for design students and tutors.

\section{SELECTING THE EXHIBITION CONTENT}

In choosing content for the Online Exhibition, it was important to find a guiding theme that would represent the diversity of the partner archives and encourage collaboration across the CETLD partnership. After visiting the four partner archives, it was clear that their common strength lay in British design of the twentieth century. Not all partners had digitised their collections to a comparable extent, which limited what existing digital material could be mined for the Online Exhibition. We considered various possible themes for the prototype exhibition, including student graduating exhibitions, institutional anniversaries and physical exhibitions at the partner institutions, but none of these allowed us to represent the richness of more than one collection. Eventually the 'design process' emerged as the most flexible, universal and feasible theme. We understand 'design process' to mean an approach to design creation through the four phases of Discover, Define, Develop and Deliver, outlined by the Design Council [5]. Archival documents related to the design process offered the potential to engage tutors from several design fields in the project, enabling them to use the material in various ways.

The two collections with best online access to images of archives were the RIBA and the University of Brighton Design Archives, but only the RIBA had a collection of digital images for which they held the copyright and that focussed on the design of one project: the Ernö Goldfinger archive for 2 Willow Road, one of the first Modernist homes to be built in Britain, now a National Trust property. Further advantages to this choice were the presence of RIBA education specialists to help develop the project with HE students and the value of the Goldfinger material as an example of a varied and extensive archive of a lifetime's design work encompassing architecture, furniture, graphic design and writing. By focusing on an architectural design from preliminary sketch to completion, the Willow Road Online Exhibition offers students and tutors various ways of approaching the material, whether from a design history perspective (i.e. situating Goldfinger's work within the context of design during his era) or from a design practitioner's point of view (i.e. examining how the house design evolved, the materials used and drawings and photographs created to document the design).

The 2 Willow Road archive is interesting for a number of reasons:

- Ernö Goldfinger's role as an advocate for Modernism in Britain 
EVA 2009 London Conference 6-8 July

Jane Devine Mejia

- His connection with European architects such as Le Corbusier and Auguste Perret

- The theme of an architect designing for himself and representing his design philosophy through a small-scale residential project

- The significance of Willow Road in architecture, three-dimensional and interior design, with its custom-designed furniture, innovative storage and room arrangements and collection of objects and artworks.

It also made sense to base our pilot exhibition around this theme because it is a 'way in' to Goldfinger's entire archive, and offers students the opportunity to appreciate the range and depth of information that can be found in such research collections. A sequence of thirty-six images was selected from the RIBA's RIBApix database of architectural drawings and photographs and from the University of Brighton Design Archives to form the core illustrative material for the exhibition.

\section{TECHNICAL CHALLENGES}

Project funding did not include a budget for software acquisition or development, on the assumption that we would use the CETLD Elgg Web 2.0 site as the host for the prototype exhibition. Elgg was adopted at the University of Brighton three years ago as the platform for its social network, Community@Brighton, one of the first in the UK to provide a shared space in which staff, students and tutors could interact. Elgg is a versatile system that provides blogging, file sharing, image presentation and social networking capabilities [6].

As the initial work began on the Willow Road Online Exhibition, we found that Elgg Web 2.0's Photo Gallery feature did not offer all the functionality needed to create a visual narrative of Ernö Goldfinger's design process. While it could display images in a slideshow format, the associated metadata could not be shown simultaneously and the images could not easily be sequenced in a specified order. Instead we explored a number of open source web album packages in the hopes of finding one that met most of our requirements. In the end, we chose Jalbum and its Fotoplayer template as the best option given time and technical constraints. Fotoplayer allowed the creation of a visually attractive slideshow with large browsable thumbnail images, space for image metadata display, enlarging, zooming and panning functions and a 'guestbook' comment box for each image [7]. Although it was not possible to run Fotoplayer from within our Elgg Web 2.0 site, we designed it to launch from an intermediary html page on the site. This hybrid approach simplified the user experience and allowed us to exploit Elgg features like blogging and file uploading while using Fotoplayer's full functionality. 


\section{EVA 2009 London Conference 6-8 July Jane Devine Mejia}

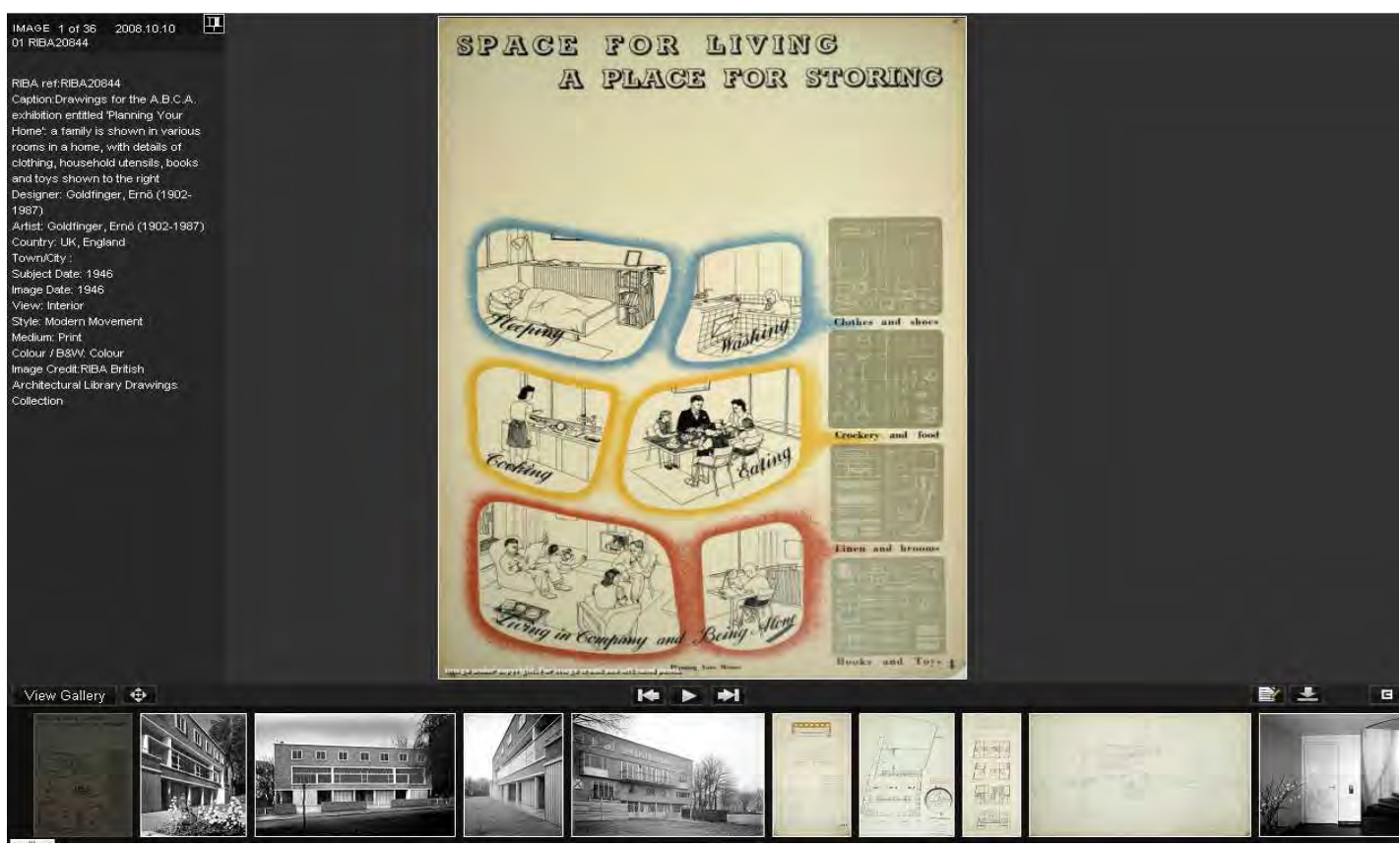

Figure 1. The 2 Willow Road Online Exhibition, using Jalbum Fotoplayer software. Images courtesy of RIBA British Architectural Library and the University of Brighton Design Archives.

\section{ENGAGING WITH TUTORS AND STUDENTS}

Finding tutors who were willing to volunteer their time and involve their students in the online exhibition research was one of the major challenges of the project. Having already defined the exhibition theme, we were in a sense working backwards, but we wanted to have something demonstrable to show tutors in order to elicit their interest in the project. We were fortunate to find a collaborator in a design tutor who was eager to involve his undergraduate students in an archives-related 'adventure' as part of the visual research class in 3D Design at the University of Brighton. While the brief for the class was that students take an object of personal significance (e.g. a watch, a purse, a doll) and explore it using a variety of visual media, the adventure gave them a chance to step outside the studio and explore something they would not otherwise encounter (in this case a Modernist house in London and its archive). These students had no background in design history and so were approaching the house purely as a design object.

In working with design students, there are a number of characteristics that distinguish them from other HE groups. In the craft-based disciplines (woodwork, metalwork, ceramics and plastics) they are predominantly female, dyslexia is a significant factor (up to $35 \%$ of students), they are makers, not writers, and so have a strong interest in materials, processes and images, rather than text. Our undergraduate group at the University of Brighton was consistent with this profile. An initial questionnaire revealed that none of the students in the 3D design visual research class had used archives before and none had any experience of online exhibitions. 
Briefly, the project was structured so that the twelve students who volunteered would visit the house at 2 Willow Road for a tour with the National Trust curator and have free time to photograph, sketch and ask questions. They then received an introduction to the related RIBA Goldfinger archival material at the V\&A Museum, this time with an education officer, who facilitated discussion and exploration of the Willow Road archive. This hands-on archive exploration and tour acted as a preparation for the virtual experience which began a week later when we invited the students to view the Online Exhibition for the first time. They were then invited to join the Elgg Web 2.0 Online Exhibitions Community where they could upload their own photographs and commentary to a password protected blog, view the Online Exhibition, write comments in the image guestbooks and share other information with the group.

We held two further meetings to see how the Willow Road experience, both real and virtual, was influencing the visual research project around their personal objects and to view the work they were producing for critiques at the end of term. In accordance with University research ethics guidelines, the students were free to withdraw from the project at any time and were not required to present their work or participate in the final evaluation meeting unless they wished to. This meant that only four attended all the meetings and presented their work at the end of term, while others filled out the evaluation questionnaires and uploaded images to the Online Exhibition blog and some chose to withdraw from the project after the second meeting. The challenge for us (and them) was how to fit a voluntary research project into the academic calendar without distracting them from course-related work.

To evaluate pedagogical impact, we asked students to complete a set of three questionnaires, to self assess their learning by asking them to evaluate their experience of the Online Exhibition and what they had learned from their encounter in the archives. An interview with their tutors also identified learning outcomes of which the students were not necessarily aware, but that were manifested in the approach to drawing, their awareness of materials and attention to the use of space in designing their projects. Although we worked with a very small group, the value lay in assessing their learning over a period of eight weeks and in seeing the work they produced during this time. While it would be rash to generalise from this sample to all practice-based design students, our observations and their questionnaire responses elucidated points that are important to consider in future work, such as the importance of images rather than text and the need for greater user control. 


\section{EVA 2009 London Conference 6-8 July Jane Devine Mejia}

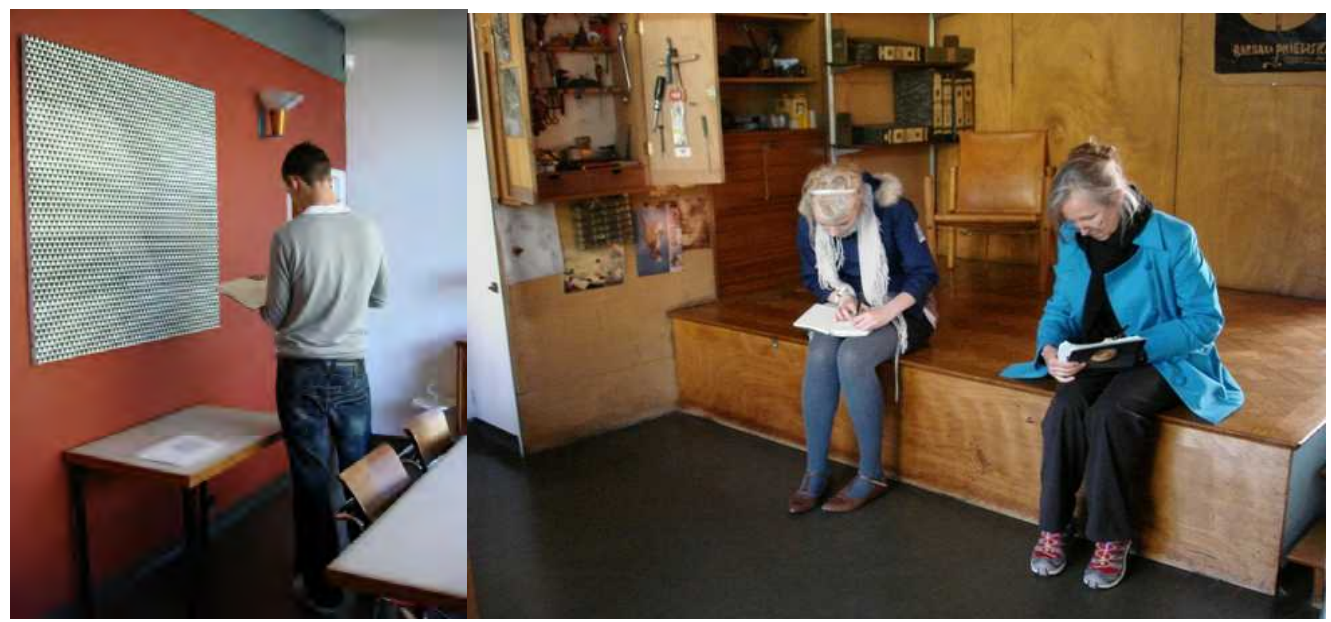

Figure 2. Students sketching at 2 Willow Road. (Photograph: the author)

\section{Learning from students}

From the second evaluative questionnaire, we determined that nine of the twelve students used Facebook, but only one used the University's Elgg Community@Brighton site. Although familiar with social networks, they did not necessarily see the point of using an academic social network that links students, tutors and staff in the same virtual environment. The assumption that students would use a social networking environment simply because they knew how was proven incorrect. Several students posted images to the Online Exhibition blog, but they did not comment on each others' postings nor contribute much text related to their own photographs. They valued the Willow Road Online Exhibition as a reminder of the archival drawings and photographs they had seen at the V\&A, as well as a complement to their experience of the house in its current form (the archives date from 1937-49).

At the same time, there was a great appreciation for the real over the virtual as a result of their contact with the National Trust Curator and RIBA/V\&A Education Officer, the physical experience of being in the house and the opportunity to examine archival drawings and learn from them. Several students wanted more time to explore the archives and to sketch in the house. Certainly the Online Exhibition did not replace the actual visit, but offered students a chance to re-examine and reflect on the material they had viewed in person. Most of them felt motivated to use archives again for design-related research after this introductory experience.

We had originally hoped to incorporate student work into the Online Exhibition, but given that the class brief did not require them to directly relate Willow Road to the visual research they produced, the link between their work and the Online Exhibition's content was not always apparent. Nevertheless their tutors saw a benefit in exposing the students to real life design research through their participation in the Online Exhibitions Project and several in the group felt that the experience had influenced their drawing, the approach to their projects and their awareness of materials. Three students produced work directly influenced by Willow Road and reported that they wanted to continue their exploration of ideas discovered there even after the project had ended. 
EVA 2009 London Conference 6-8 July

Jane Devine Mejia

After completing the work with the BA 3D Design students from the University of Brighton we undertook a second project, this time with Royal College of Art (RCA) MA History of Design tutor and students. With this group, we also visited 2 Willow Road and viewed the RIBA archive at the V\&A. The students then had the option of choosing themes that interested them and developing PowerPoint mock-ups of their own virtual exhibitions on a very small scale. The goal was to give them the opportunity to think about archives and curatorship in an online environment. In contrast to the undergraduate cohort, this group was trained in contextual research and approached the house from a historical and theoretical standpoint. The RCA students were highly critical of the images they viewed online and were aware of the strengths and weaknesses of the archive; whereas the undergraduate 3D design students accepted the images for their informational and design-related value. The RCA students contributed valuable ideas for ways of further developing the Online Exhibition; however it was evident that they did not need an introductory archives experience through the Online Exhibition as they were already proficient researchers. This helped us to confirm that the primary audience for the Online Exhibitions Project should be undergraduate practice-based students who were unfamiliar with archives, rather than postgraduate design history students with established archival research knowledge.

\section{CONCLUSION}

Online exhibitions offer the potential of demystifying the archive and making it relevant to students as a source of design research. Our project enabled design students to explore and learn from archival material on site and in a virtual environment. The Online Exhibition dissolved some of the physical boundaries that deter students from using archives: opening hours, location, fragility of materials and handling restrictions, the need to know what to request and to accept archivist mediation of research (i.e. the lack of browsability) by enabling them to engage in self-directed exploration of the Willow Road archive. The Online Exhibition and its associated blog also invited student participation and the sharing of creative work, ideas and informal images taken on the tours.

Despite these advantages, the technology employed did present some frustrations for the project leader, the tutors and the students. We could not, for instance, enable users to organise the images and add their own photographs, drawings and narratives, because the Fotoplayer software that we used did not permit re-sequencing of the images or editing and commenting on existing descriptive text. RIBA copyright restrictions meant that we could not link the Willow Road Online Exhibition to our public website. The opportunity for students as curators was also not fully developed, in part due to time restrictions and because of the technological limitations on user participation described above. We wanted the students to have the security and freedom of working in a password protected Web 2.0 environment rather than a public website; however wider access after their project was finished would have been desirable, both to encourage other HE groups to interact with the Online Exhibition and to promote general awareness of archives to the HE design community. 
EVA 2009 London Conference 6-8 July

Jane Devine Mejia

From a broader perspective, the Online Exhibition created the expectation among users that online access to the partner archives was more transparent than is in fact the case. Navigating between online catalogues, printed finding aids, virtual image collections and the actual archive is complex for those outside (and even within) the institutions. Virtual collections only represent a fraction of the institutions' physical holdings. For instance, the RIBApix database contains some 30,000 images, whereas the RIBA holds over 2 million drawings, photographs and other archival documents. Similarly the V\&A Archives of Art and Design are only beginning to add their holdings to the museum's 'Search the Collections' public interface. A student researcher must be determined and diligent to get beyond these hurdles and approach the actual archival collections.

Developments like the Flickr Commons, the public domain image space pioneered by the Library of Congress on the popular photo sharing website, are attempting to bring archives to existing user groups, rather than expecting users to come to them. Similarly the V\&A is a partner in the new Creative Spaces National Museums Online Learning Project, which links users with nine UK museum collections in a Flickr-like environment. The Royal College of Art's online ShowGallery of student work will go public later this year, albeit not in a Web 2.0 environment. Similarly, the University of Brighton is using the Archives Hub and the Visual Arts Data Service (VADS) to bring images and descriptions of its collections to researchers worldwide. In the final stage of our project, we will concentrate on using lessons learnt to make recommendations on a sustainable and reusable online exhibition framework for the CETLD partner archives. We anticipate that participative online exhibitions, such as the one we are developing in the CETLD Elgg Web 2.0 environment, will be another medium for bringing archives and users closer together and for opening archives to new audiences in higher education, particularly those in practice-based disciplines.

\section{ACKNOWLEDGEMENTS}

Many people have contributed to our project over the past 18 months. I would like to thank the following for their time and valuable advice: CETLD: Sina Krause, Roland Mathews, Jos Boys, Catherine Speight and Heloisa Candello; University of Brighton: Catherine Moriarty, Stan Stanier, Patrick Letschka, Jacqui Chanarin and the second year 3D Design visual research class; Royal College of Art: Neil Parkinson, Chris Mitchell, Jeremy Aynsley, Harriet McKay and the MA History of Design students; Royal Institute of British Architects: Robert Elwall, Susan Pugh, Paul Snell, Catherine Duncumb (RIBA/V\&A); Victoria and Albert Museum: Christopher Marsden, Abraham Thomas; National Trust: Rebecca Milner.

\section{References}

[1] The CETLD website (http://cetld.brighton.ac.uk) provides details of the 40 research projects undertaken since 2005.

[2] For Museums and the Web online exhibitions award winners (1997-2008), see http://www.archimuse.com/conferences/mw.html. The nominees and winners are listed on each annual conference's site. 
[3] Among the few to incorporate HE student involvement in its online exhibitions is the Virginia Center for Digital History through the projects it has developed with undergraduates http://www.vcdh.virginia.edu/index.php?page=Projects, including the Thomas Jefferson site (http://www.jeffersonstravels.org/).

[4] Fine Arts Museums of San Francisco, MyGallery http://www.famsf.org/gallery/index.asp and the Metropolitan Museum of Art, New York, My Met Museum http://www.metmuseum.org/mymetmuseum/

[5] DESIGN COUNCIL. Eleven lessons : managing design in eleven global companies. Desk research report. London: Design Council (5 November 2007), p.10. This report provides a summary of design process research to date.

[6] Elgg was developed by Ben Werdmuller and David Tosh in 2004. For more information on the current version, see http://www.elgg.org/

[7] Fotoplayer is an open-source Flash-based tool developed by Dhinakaran Annamalai. For more information, go to http://www.fotoplayer.com/ 